\title{
UMA ABORDAGEM ALTERNATIVA PARA O ENSINO DA TRANSMISSÃO E RECEPÇÃO DE ONDAS ELETROMAGNÉTICAS ${ }^{*}$
}

Rodrigo T. Rossini ${ }^{1}$

\section{INTRODUÇÃO.}

Estudar a transmissão de uma onda eletromagnética (OEM) nos leva a um novo mundo e uma nova maneira de enxergar a propagação de informações e dados. O aluno que hoje vivencia este estágio da humanidade é bombardeado com novas tecnologias da informação e comunicação (TIC's). Conceitos surgem, siglas e formas de se comunicar emergem, e no meio deste emaranhado está o aluno, o qual muitas vezes é o público de maior potencial de utilização destas ferramentas que são amplamente utilizadas, mas seus princípios científicos e de funcionamento são pouco explorados e compreendidos na escola. Desta forma, por que não explorar alguns conceitos relacionados a estas tecnologias em sala de aula?

\section{PRINCÍPIOS BÁSICOS.}

Com o desenvolvimento do eletromagnetismo e seus desdobramentos, a humanidade criou as bases teóricas para a propagação de ondas eletromagnéticas. Algumas de suas aplicações serão discutidas neste momento como base para este trabalho, discutindo apenas alguns aspectos gerais e relevantes a esse assunto, usando de analogias e figuras na tentativa de evitar certos formalismos matemáticos. Começaremos nossa discussão estudando um sistema de comunicação bási-

${ }^{*}$ DOI - 10.29388/978-65-86678-08-6-0-f.61-72

${ }^{1}$ CTUR, UFRRJ. E-mail: rossinirtr@ufrri.br 
ca, onde as presenças de alguns elementos são indispensáveis e representados na figura 1.

Figura 1. Diagrama em blocos de uma comunicação analógica simples.

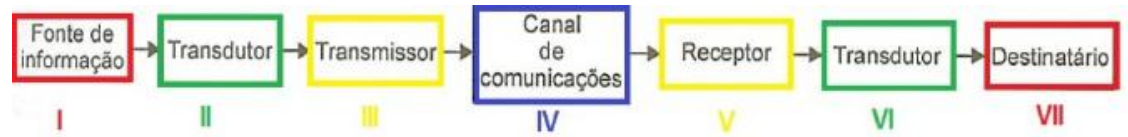

Fonte: Elaborado pelo autor

Como um simples exemplo da figura 1, analisaremos a comunicação entre duas pessoas através de um sistema de telefonia analógica convencional, representado pela figura 2 .

Figura 2. Comunicação através da telefonia analógica.

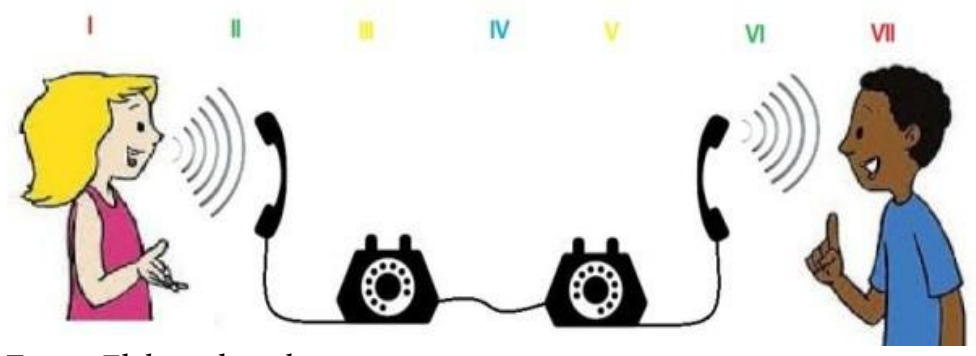

Fonte: Elaborado pelo autor

Cada passo dessa comunicação tem um correspondente ao diagrama em blocos anteriormente exposto:

- I) Fonte da informação: geradora da mensagem que neste caso é a menina da figura 2;

- II) Transdutor de emissão: que neste caso é o microfone convertendo as vibrações mecânicas do som em sinais elétricos;

- III) Transmissor: é a parte interna do circuito do telefone que oferece condições para que o sinal elétrico percorra o canal de comunicação; 
- IV) Canal de comunicação: é o meio físico por onde as mensagens em forma de sinais elétricos trafegam, indo do transmissor ao receptor;

- V) Receptor: é a parte do circuito interno do telefone de recepção que recebe os sinais elétricos e os direciona ao transdutor de recepção;

- VI) Transdutor de recepção: componente que converte os sinais elétricos recebidos em vibrações mecânicas (som) para o destinatário;

- VII) Destinatário: recebedor do sinal sonoro que, neste caso, é o menino da figura 2.

Para um sistema simples de comunicação baseado em ondas eletromagnéticas, a situação é parecida, em vez de um sinal elétrico percorrer um canal cujo meio é um fio, dessa vez o que será transmitido será uma onda cujo canal será agora o meio em que essa onda se propaga, geralmente o ar ou o vácuo.

Figura 3. Esquema básico de comunicação via rádio

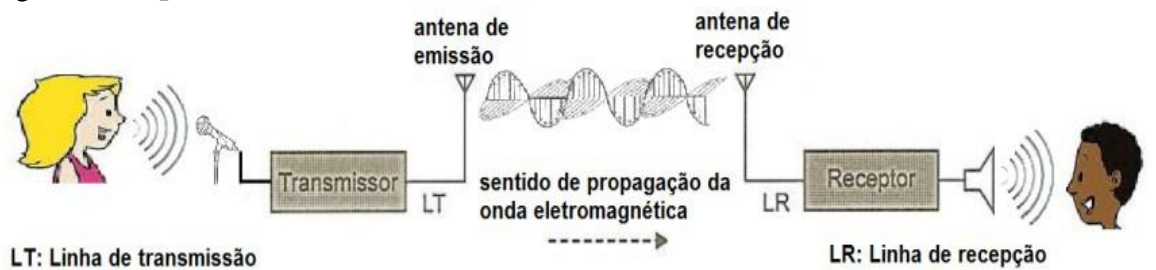

Fonte: Elaborado pelo autor

Como realizamos uma transrecepção de uma OEM? Basicamente, quando temos uma carga acelerada periodicamente em uma antena, a mesma gera, em certas condições físicas e de engenharia, uma onda periódica que se propaga até atingir a antena de recepção ${ }^{2}$.

\footnotetext{
${ }^{2}$ Para evitar formalismos matemáticos e obter uma noção básica e visual do fenôme no, sugiro ao leitor a visualização de duas simulações interativas contidas no sítio https://phet.colorado.edu/pt BR/ cujos nomes são: Irradiando carga, Ondas de Rádio e Campos eletromagnéticos.
} 
Por conta da chegada da onda na antena de recepção, elétrons começam a se mover nessa antena, enviando sinais ao circuito receptor o qual será responsável por enviar a mensagem ao transdutor de recepção e consequentemente ao destinatário. Junto a isso, qual seria a melhor forma ou técnica para enviar informações entre transmissor e receptor? Uma das técnicas mais rudimentares em telecomunicações para atingir esse objetivo é a de comunicação via código Morse. Nela, um sinal ou onda transmitidos eram chaveados ${ }^{3}$ a fim de se criar uma informação inteligível pelo receptor. Sua velocidade de transmissão da informação dependida da capacidade de chavear a fonte de energia e da capacidade de interpretação dos sinais que chagavam ao receptor, criando assim, um limite operacional relativamente baixo.

Figura 4. Esquema básico de comunicação utilizando código Morse.

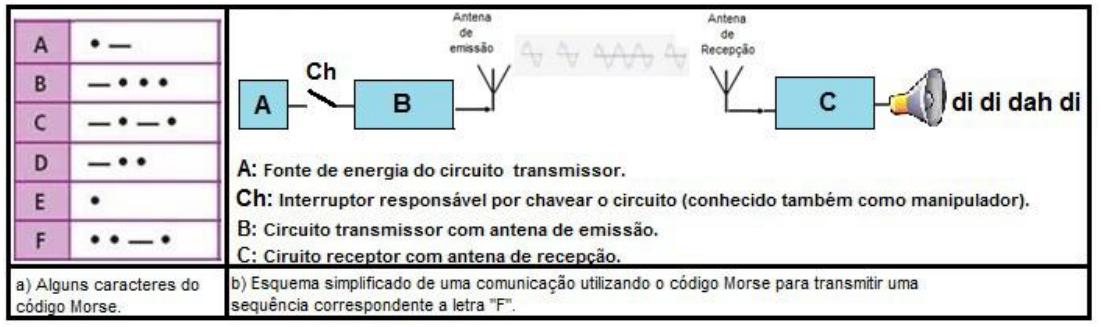

Fonte: Elaborado pelo autor

Apesar de mesma natureza, a OEM emitida pela antena emissora é de frequência bem menor do que a luz visível. Desta forma, faremos algumas analogias com uma fonte de luz visível para facilitar a visualização. Nestas analogias, o circuito emissor e sua antena serão substituídos por uma lanterna de luz polarizada, monocromática de cor verde e toda a recepção será substituída pela visão humana ${ }^{4}$. No caso da comunicação via Morse, a mensagem seria transmitida desligando e ligando sucessivamente a lanterna em intervalos curtos e mais longos de tempo a fim de se criar os códigos exemplificados na figura

\footnotetext{
${ }^{3}$ Processo pelo qual uma espécie de interruptor é ligado e desligado para fim de estabelecer ou interromper o processo de transmissão de uma OEM.

${ }^{4}$ Chamaremos de visão humana todos os órgãos nervos e entidades responsáveis pelo processamento da imagem pelo homem, desde o olho humano até o cérebro.
} 
4(a). Sendo estes códigos interpretados pela visão humana como sendo as letras e caracteres responsáveis pela comunicação.

Com o passar do tempo, outras formas de transmitir informações surgiram no intuito de aumentar a eficiência na transmissão e recepção de sinais e superar problemas de engenharia. Essas formas ou técnicas de transmissão são chamadas na maioria dos casos de modulação sendo definida como:

\begin{abstract}
"Processo pelo qual uma propriedade ou característica de um sinal é modificada conforme um outro sinal (que contém a informação a ser transmitida), a fim de se obter maior eficiência de transmissão (LAMAR, 2005) "
\end{abstract}

Então se tomarmos uma representação simples do campo elétrico ${ }^{E(t)}$ de uma OEM emitida como sendo da forma $E(t)=A(t) \cdot \cos [\omega(t) \cdot t+\phi(t)]$ podemos embutir o sinal desejado (informação ou mensagem) em alguns de seus parâmetros conforme figura 5 .

Figura 5. Alguns tipos de modulações analógicas.

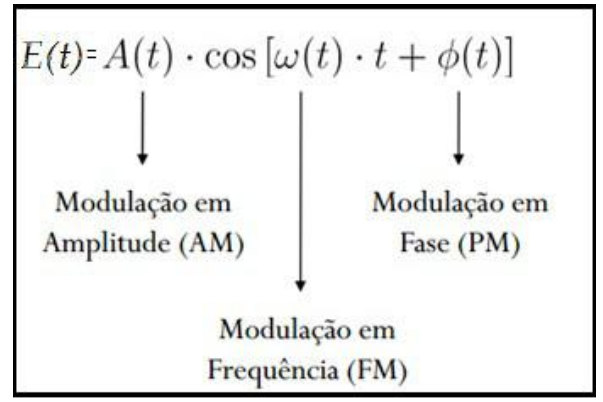

Fonte: Elaborado pelo autor

Em que o sinal de maior frequência onde a mensagem será embutida é chamado de portador (ou onda portadora), o sinal ou mensagem que será embutido é chamado de modulante (ou onda modulante) e o sinal resultante já com o sinal embutido é chamado de modulado (ou onda modulada). Tomaremos como exemplo dois tipos tradicionais de modulação: a modulação AM (Amplitude Modulada) e a mo- 
dulação FM (Frequência Modulada). Nesses, os parâmetros a serem modificados serão respectivamente a amplitude e a frequência da onda transmitida. Desta forma, consideraremos um exemplo simples onde o sinal a ser transmitido (informação ou mensagem) seja uma onda harmônica simples $\mathrm{m}(\mathrm{t})$ que alterará o parâmetro da amplitude $\mathrm{A}(\mathrm{t}) \mathrm{da}$ onda original (portadora) conforme figura 6.

Figura 6. Modulação em amplitude de um sinal harmônico simples.

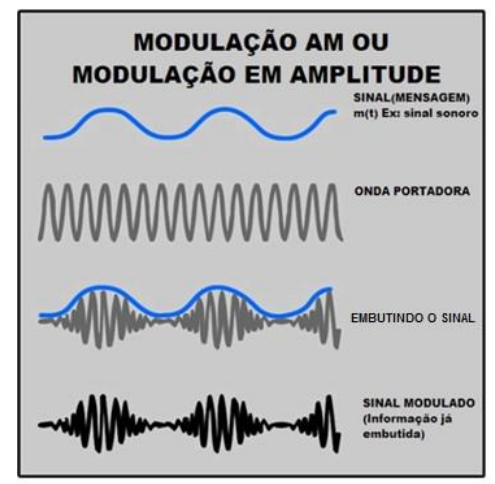

Fonte: Elaborado pelo autor

Imaginemos um sinal sonoro senoidal (onda mecânica) sendo captado pelo transdutor de emissão (microfone) e que é transformado em sinal elétrico. Este sinal, através do circuito transmissor, modifica a onda transmitida pela antena de emissão. Esta onda, chamada agora de modulada, se propaga pelo espaço livre até interceptar a antena de recepção. Com isso, o sinal elétrico gerado na antena de recepção após a chegada da onda modulada é tratado pelo circuito do receptor o qual se encarregará de separar a mensagem do sinal modulado e entregá-la ao transdutor de recepção (alto-falante).

Figura 7. Esquema simplificado de uma transmissão em AM de um sinal harmônico.

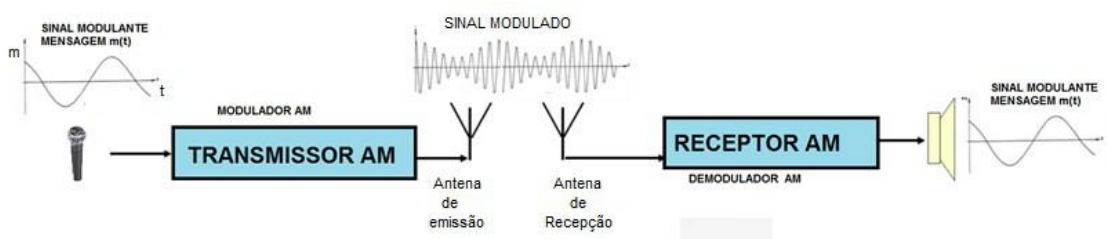

Fonte: Elaborado pelo autor 
Para uma segunda análise desta técnica, utilizaremos novamente uma lanterna e a visão humana, definidas anteriormente, como respectivamente sendo a transmissão e a recepção de uma OEM. Nessa analogia, percebemos que ao ligar a lanterna, a única informação per cebida pela visão humana é a chegada da onda eletromagnética. Para que outras informações sejam percebidas, parâmetros da luz emitida devem ser alterados para que essas alterações sejam interpretadas pela visão como sendo novas informações. Desta forma, como a modulação em AM seria percebida e interpretada pela visão? Para tal, sabemos que a intensidade de uma OEM depende de sua amplitude da forma:

$$
I=\frac{1}{c \mu_{0}} E_{r m s}^{2}
$$

Desta maneira, ao embutirmos a mensagem no parâmetro da amplitude da onda, a visão humana perceberia uma luz com sua intensidade luminosa variando entre um mínimo e um máximo, onde cada valor de intensidade seria interpretado como uma parte da informação transmitida ${ }^{5}$. A mensagem funcionaria como uma espécie de DIMMER $^{6}$ interligado a lanterna e responsável por variar a intensidade luminosa da luz emitida pela mesma. Um desdobramento óbvio desta ideia é embutir a mensagem em outro parâmetro da OEM transmitida pela antena de emissão, como, por exemplo, alterar a frequência desse sinal ou onda enviados. Por simplicidade, iremos supor novamente que a mensagem é novamente uma onda harmônica que, ao variar entre um valor mínimo e máximo de amplitude, consequente-

\footnotetext{
${ }^{5}$ Sabemos que na prática, a visão humana reconhece um número máximo de quadros em um determinado tempo, podendo alterar a percepção da variação de intensidade da onda pela visão. Por isso, ignoraremos esse fato para o funcionamento da analogia.

${ }^{6}$ Dispositivo de uso geralmente doméstico que junto ao interruptor é responsável por alterar a intensidade de corrente elétrica em aparelhos eletrodomésticos e lâmpadas, mudando a luminosidade do ambiente e velocidade de funcionamento de aparelhos.
} 
mente fará com que a onda emitida pela antena emissora (portadora) varie sua frequência também entre um valor mínimo e máximo.

Figura 8. Modulação em frequência de um sinal harmônico simples.

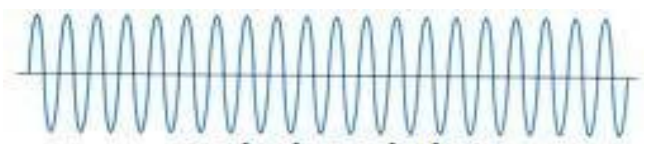

onda da portadora

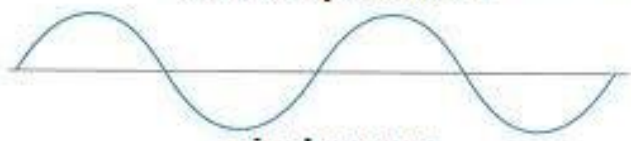

sinal sonoro

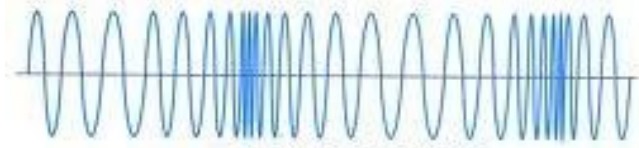

sinal modulado

Fonte: Elaborado pelo autor

Fazendo outra analogia com a luz visível, em que a frequência da onda emitida é transladada para faixa do visível, a onda emitida (luz) agora pela lanterna sofrerá um desvio em sua frequência. Esta luz inicialmente definida na cor verde sofrerá um desvio que tenderá para o vermelho quando o valor da frequência for mínimo, e um desvio de frequência para o violeta quando o valor de frequência tender ao máximo. A visão humana, responsável pela recepção, perceberá cada mudança de cor como uma modificação da informação inicial onde cada tonalidade de cor pode ser interpretada como uma parte diferente da informação.

\section{UTILIZANDO EXPERIMENTO DE BAIXO CUSTO}

O objetivo deste tópico é mostrar as características e a montagem do aparato experimental usado neste trabalho os quais foram pensados para terem um baixo custo e serem empregados em sala de aula. 


\subsection{Testando o experimento.}

Para testar o experimento, posicionamos a ponteira laser em frente a fotocélula. Ao ligarmos o circuito transmissor e o receptor, notaremos que o feixe do laser atingirá a fotocélula. Em uma nova etapa, executaremos uma música no celular do transmissor. Se tudo estiver correto, o sinal de áudio sairá das saídas de fones de ouvido do celular e percorrerá um dos lados do transformador de áudio. Como o sinal de áudio é variável, o transformador de áudio realizará sua função e induzirá no seu outro lado o sinal de áudio do smartphone. Com isso, a intensidade do laser variará conforme o sinal de áudio proveniente do celular. Esta intensidade de luz variável provocará uma tensão variável nos terminais da fotocélula e consequentemente um sinal no alto-falante do circuito receptor.

Figura 9. Esquema de funcionamento do experimento.

ESQUEMA DE FUNCIONAMENTO DO COMUNICADOR A LASER

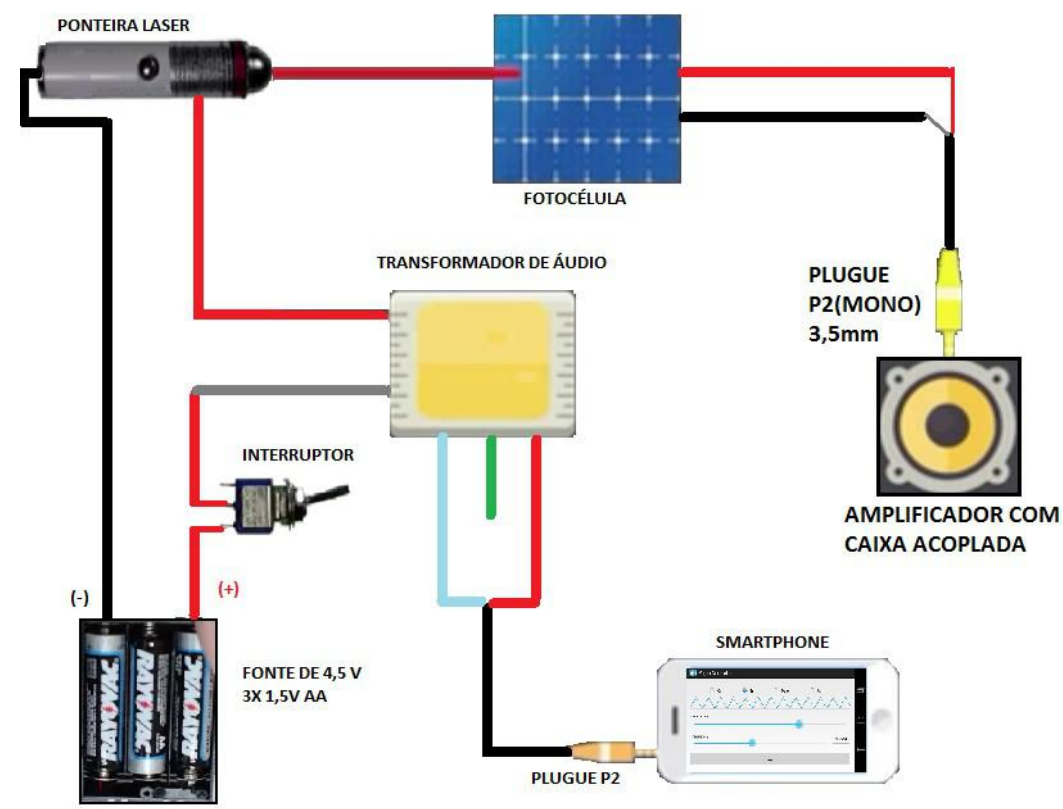

Fonte: Elaborado pelo autor 
Para melhor funcionamento do experimento, diminua a intensidade da luz ambiente ou faça uma caixa protetora que não deixe a luz ambiente incidir sobre a fotocélula.

\subsection{Proposta de uma adaptação para um aluno com deficiência visual.}

O experimento de baixo custo proposto anteriormente é inicialmente uma proposta alternativa para o ensino da transmissão de uma OEM para o ensino médio e de jovens e adultos (EJA). Porém, como adaptaríamos este experimento para alunos com deficiência visual? Em seu trabalho, Azevedo (2012) introduz uma série de formas de se introduzir o ensino de óptica para alunos com deficiência visual, utilizando-se de quadros magnéticos e lasers para esse objetivo. Neste contexto, a própria definição de luz e de uma OEM teria que ser modi ficada para esse fim.

[...] o professor pode ajudar o estudante introduzindo a luz como o agente intermediário na interação à distância entre uma fonte (o sol ou o ponteiro laser) e o receptor (a pele de estudante). Aqui, a definição operacional para a luz como "a radiação detectada pelo olho humano" não faz sentido para o aluno cego. Com base na etapa anterior, sugerimos uma nova definição: "A luz é uma forma de energia radiante que impressiona a sua pele pelo tato.(AZEVEDO,A,C 2012)'

Em seu trabalho, Azevedo (2012) usa dessa nova definição para criar intensidades do laser incidente no braço do aluno. Com isso, podemos criar uma concepção adaptada do que seria a modulação AM. Inserindo esse público no cotidiano e de tecnologias usuais da sociedade moderna. 


\section{CONCLUSÃO.}

A transposição didática que tem que ser feita para adequar as novas tecnologias ao cotidiano do aluno nem sempre acontece em sala de aula. Por isso, o objetivo deste tema foi trazer aspectos básicos de uma tecnologia que continua em evolução e pouco abordada em sala de aula. Então, o maior objetivo após o aprendizado do tema é criar um enculturamento científico no aluno. Deste modo, se ao final da aplicação desta proposta o aluno tiver condições de interpretar o mundo relacionado ao tema de uma forma mais consciente, tendo uma noção crítica dessa tecnologia que o cerca, a missão deste trabalho terá sido cumprida.

\section{REFERENCIAS.}

AULAS online de CW. Propagação aberta, 2015. Disponível em: $<\underline{\text { http://propagacaoaberta.com.br/novidade-curso-aulas-online-de- }}$ cw-codigo-morse/>. Acesso em: 3 nov. 2015.

AUSUBEL, D. P. The psychology of meaningful verbal learning. New York: [s.n.]. 1963.

AZEVEDO, A.C. Produção de material didático e estratégias para o ensino de física para alunos portadores de deficiência visual, Dissertação (Mestrado em Ensino de Física), UFRJ, Rio de Janeiro 2012

BALANIS, C. A. teoria de antenas. 3. ed. Rio de Janeiro: LTC, 2009.

BRUSCATO, G. C.; MORS, P. M. Ensinando física através do radioamadorismo. Revista Brasileira de Ensino de Física, Porto Alegre, v. 36, n. 1, março 2014.

EFÍSICA. Noções elementares sobre ondas eletromagnéticas. e-fisica, 2007. Disponível em: $<$ http://efisica.if.usp.br/eletricidade/basico/ondas/ondas eletromagneticas/>. Acesso em: 2 out. 2015.

FONTANA, E. Radiação e antenas, Recife, 2013. 
LAMAR, M. V. Modulaçâo em amplitude, Universidade Federal do Paraná -Dep. de Engenharia Elétrica, 2005.

MEDEIROS, J. C. D. O. Princípios de telecomunicações. 2. ed. São Paulo: Érica, 2007.

MOREIRA, M. A. O que é afinal aprendizagem significativa?, Porto Alegre, 2012.

NUSSENZVEIG, H. M. Curso de física básica. São Paulo: Blucher, v. 3, 1997.

OTERO, M. R. ¿Cómo usar analogías en clases de física? Cad. Cat. Ens. Fís., v. 14, n. 2, p. p. 179-187, 1997.

PEREIRA, S. Modulação am e fm. Ebah, 2011. Disponível em: $<\underline{\text { http:// }}$ www.ebah.com.br/content/ABAAABqjUAI/modulacao-am-fm $>$. Acesso em: 2 maio 2015.

PIROPO, B. Modulação AM e FM. IT FORUM 365, 2014. Disponível em: <http://itforum365.com.br/blogs/post/113330/telefones-modulacao-am-e-fm>. Acesso em: 4 nov. 2015.

PORTAL EXPLICATORION. Heinrich Hertz. Portal Explicatórion, 2015. Acesso em: 1 maio 2015. Disponível em: <http://www.explicatorium.com/biografias/Biografia Heinrich Hertz.php $>$ Acesso em: 26/01/2015.

RESNICK, H. Fundamentos da física. Rio deJaneiro: LTC, v. 4, 2009. ROSSINI, R. T Transmissão e recepção de ondas eletromagnéticas: uma abordagem experimental para o ensino médio e técnico. Dissertação (mestrado Nacional em ensino de Física) UFRJ Rio de Janeiro, maio de 2016

TELECO. Ciclos Evolutivos: Grandes Descobertas. TELECO, 2015. Disponivel em: $<$ http://www.teleco.com.br/tutoriais/tutorialciclos/pagina 2.asp >. Acesso em: 17 abr. 2015. 